\title{
Study on Endogenous and Our Audit Risk Assessment
}

\author{
Jing Liu ${ }^{1, a}$, Lijia Huang ${ }^{2, b}$ \\ ${ }^{1}$ JiangXi Normal University Business College, P.R. China, 330022 \\ 2 JiangXi Normal University Business College, P.R. China, 330022

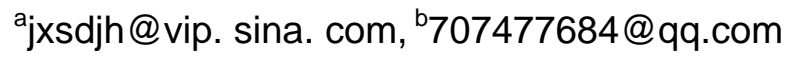 \\ * Jing Liu
}

Key words: Audit risk; Endogenous; Evaluation Index; Assessment method

Abstract. Auditing is a specialized, economically independent supervision behavior, the risk not only affects the interests of the audited entity and stakeholders but also seriously restrict the healthy and stable manner rapid development of social and economic. Based on the analysis of the endogenous of audit risk, the level of audit risk assessed, and how to control the audit risk were discussed.

\section{Introduction}

Audit is a systematic review process, through the audited entity financial statements as well as monitoring of its economic activity takes place the authenticity and legality, so as to achieve specification the audited entity's business transaction. Risk through the entire audit process, the risk of such a serious impact on the interests of the audited entity and all stakeholders, but also affect their sustainable development in the national economy. Audit risk is an important aspect of major industry, enterprise management and the analysis of the causes of audit risk measurement and control is extremely necessary.

\section{Defining the concept of audit risk}

Early 1980s, audit and audit system gradually restored, and the risks associated with the audit process produces. Audit risk is CPA failed to uphold the principles of an authentic legal and reasonable to reveal significant errors exist statements in the process of reviewing the financial statements. CPA is not reflected in the report of the falsity of the business, erroneous truly revealed. Generally it showed the presence of the main economic business misstatements, omissions, addition in the statement. The main risks are inherent risk, control risk and detection risk, the first two risk are the risk of the audited entity produced in the statement generated, then a risk that the audited entity in the process of the review statement, due to various of factors cause misjudgments and stakeholders to provide comments are not fair.

\section{Endogenous of Audit Risk}

In recent years, the audit risk and industry has become the focus of social concern and caused many economists deep thoughts. From the entire audit process, the audit activity by a variety of obstacles, the risks also increased.

\subsection{Increasing business risk}

With the rapid development of economic, increasing market competition, enterprises in order to survive in this harsh environment, we will certainly expand the business, and constantly develop new products or provide new services in order to achieve higher economic returns, improve operational efficiency. At the same time, the accounting policies and regulations are constantly improved and updated, the audited entity in the implementation of non-standardized and untimely response to this rapidly changing requirements of the times, will inevitably lead to rising business risks, and thus indirectly affect the audit risk. 


\subsection{Imperfect internal control systems}

Internal control system is not just a system, but also a philosophy. Overall poor quality of the company's financial officers, financial basis is too weak to work, their oversight regulation, which will make the audit risk beyond reasonable limits. The presence of the governance structure of the audited entity are serious flaws in the internal control system is not strict, a "re-form, light execution," the state administration, it is difficult to find in the control of economic activities in the presence of errors and fraud. Thus directly affect the audit risk, hinder the sustainable development of enterprises.

\subsection{Auditor practice standards and low quality}

In this society to accelerate the process of development, the prevalence of a "qualified, no experience," the novice in the workplace auditing activities; For its part, it has the expertise is not enough, if the lack of strong operational capacity, what kind of audit approach, how to collect evidence in audit process, will be greatly hindered, so that the auditors issued audit reports and opinions and the real situation will be very biased.

\subsection{Audit process is not rigorous}

Audit activity is not easy to success, but after a period of time through the audited entity economic business to be verified. Audit evidence and methods throughout the audit process. Today many of the audit team has a lot of people who don't have the knowledge to participate in the audit, so that the process is not rigorous; adopting the method of sampling audit, the audit evidence obtained by itself is not comprehensive, and there are many omission; Improper use of the legislation in the process of auditing, so that the audit evidence distortion. Therefore the audit report issued didn't desirability.

\subsection{Accounting firms tempted by other costs}

In recent years, the rapid development of accounting firms, business competition is increasingly fierce. The main audit activities will be charged a fee from the audit entity; however, audit fees don't have a rules-based standards. part of accounting firm audit should follow the objective, fair and independent principles throw behind, in order to cater to is illegal requirements from the audited entity. In addition to the audit fee to obtain a rebate from the audit of the audited entity.

\section{Construct audit risk assessment system}

Based on the above causes of audit risk. This paper from three aspect of the inherent risk, control risk and detection risk, under the principle of relevance, feasibility, comprehensive building assessment system of audit risk.

\subsection{Inherent risk}

There are conduct and competence of staff, status of personnel changes, abnormal pressure, nature of Business, managers style, environment factor and other related indicators set. Conduct and competence among employees is reflected in the experience, experience, overall quality and ability in all aspects of staff; Status of personnel changes reflect changes in management personnel changes, especially financial officers; Abnormal stress response managers under pressure from their own poor business conditions; nature of business reflects business expansion, increasing the high-risk business, the more significant nature complex and diverse; manager's style reflects the manager has a unique personality and leadership style; changes in macro and micro environmental factors reflect market conditions, increased competition and changes in demand.

\subsection{Control Risk}

There are business Implementation, employment standards officer, information and communication, reasonable degree program, reasonable organization structure and supervision mechanism set up the organizational structure of information related indicators. The status of implementation is reflect the 
implementation of the business banking cash; Employment standards officers to reflect the process of hiring new personnel comprehensive survey of all aspects of quality; Information and communication is reflected information and communication of the audited entity and recording reflected the relevant files, documents, books; Reasonable degree programs reflect the development of rational management of the program; Oversight mechanisms reflect the reasonable and efficient supervision management mechanism of the audited entity.

\subsection{Check Risk}

There is proportion ofscientific methods, reduce error rates, ability of auditors, pressure of auditors, quality of auditors. The scientific method reflect that select a sample method should be scientific and effective; Reduce the error rate reflects minimize mistakes; The ability of auditors to reflect practitioners have a certain level of qualification; Pressure of auditors reaction it from government accounting firms and some of external environment; Quality of auditors reflected has always been adhering to the independent, objective and impartial manner in the audit process.

\section{Comprehensive Evaluation of Audit Risk}

Three dimensions under the audit risk and its associated factors. Please team of experts to audit risk indicators scoring. In order to reduce subjective judgment brought by the unnecessary errors and increase accuracy, adopt expert opinion method, provided the major factors $\mathrm{Ai}=\{\mathrm{Ai} 1, \mathrm{Ai} 2 \ldots$ Ain \}, according to multiple experts by oneself to assess these factors. In most cases by having a 1-4 scale or a scale of 1 to 5 scale is represented. Based on actual needs, using the scale of 1 to 5 , the index is divided into grades 1 to 5 , a clear reflection of the content index for each grade level trends, specific requirements, and to establish the correspondence between the various grades of between attributes, each file according to the degree of trend content corresponding evaluation index value of 1 to 5 minutes, the first gear (high) corresponding to the index evaluation is 5 points, the second tranche (high) 4 points, the third gear (reasonable) as 3 points, the fourth gear (low) 2 points, the fifth gear (low) to 1 minute. Statistics membership of the indicators after the end of score. And a plurality of experts to the weight you measured as the average weight of audit risk weight. Combined with the actual situation of enterprise, the audit risk is determined.

\section{Conclusion}

Audit risk associated with the entire audit activities, hinder the development of the audit industry, and socio-economic development. Audit risk is an important part of the entire audit process closely watched. In terms of risk prevention conducted a preliminary attempt, and achieved good results, but the risk of the whole audit activities, it still affected by many factors. The inherent risk is the risk that is the objective existence in the course of the audit entity management, and it is affected by the internal and external environment; Control risk is the risk by the enterprise internal control system defects caused. The major defects promote the growth of the errors and false phenomenon. Check risk is the CPA failed to find corporate financial statements for errors in the audit process and the only risk factors can be controlled by the CPA. We should be from three aspects of inherent risk, control risk and inspection risk to scientific assessment our audit risk under the principle of objectivity, fairness, independence.

\section{Reference}

[1]Warren.Using Date Mining Techiques in Auditing [J]. The Audit and control,2006(7).

[2] Cui Changshun modern M \& Audit and Risk Management [J] modern commercial, 2014, (36): 175-176.

[3] Zhuang Xiaoping risk of internal audit of state-owned enterprises control [J] financial sector, 2014, (26): 248-249. 
[4] Huang Gege, Tang Liru research significance and preventive measures against internal audit risk [J] managers, 2014, (30): 49.

[5] Yang Xiao-min. Internal audit of state-owned enterprises and countermeasures [J]. Market Weekly (theory),2014, (1): 84-85. 